\title{
CONSUMO E DESCARTE DE RESÍDUOS ALIMENTARES EM UM BAIRRO DO MUNICÍPIO DE CAXIAS DO SUL/RS
}

\author{
Marcelo Zaro* \\ Rejane Margarete Schaefer Kalsing ${ }^{* *}$ \\ Heloísa Theodoro ${ }^{* * *}$
}

\begin{abstract}
Resumo: O desperdício de alimentos apresenta diversos aspectos negativos do ponto de vista ambiental, econômico, social e ético. O objetivo desse trabalho foi coletar informações com famílias de um bairro de Caxias do Sul/RS com relação ao consumo e descarte de resíduos alimentares, através de questionários. Os resultados indicaram que 42,1\% dos respondentes percebem o desperdício de alimentos em casa, e 36,8\% compram além do planejado na rotina de compras. Sobre o destino dos resíduos alimentares, destaca-se o reaproveitamento em outras refeições e a destinação à coleta pública. Constata-se uma limitação de informações sobre o tema que, entre diversas razões, também é resultado da pouca atenção dada ao assunto até então, e uma carência em termos de programas de sensibilização. Por fim, são sugeridas ações de educação ambiental sobre o assunto, que ainda são escassas no Brasil, assim como o incentivo à compostagem nos domicílios.
\end{abstract}

Palavras-chave: Desperdício de alimentos. Educação ambiental. Consumo. Resíduos Sólidos. Gestão.

\section{Introdução}

O desperdício de alimentos é um problema que passou a ser discutido com constância em função da necessidade imediata da erradicação da fome em muitos países ou regiões vulneráveis em termos socioeconômicos, e de problemas ambientais crescentes, como a geração de resíduos sólidos, líquidos e gasosos. A preocupação com a escassez de alimentos, entre outros recursos naturais, e o aumento da população mundial (consumidora), também contribuíram para chamar a atenção de gestores públicos e do meio científico para o tema, bem como os questionamentos da população e das organizações, em geral.

Um agravante dessa situação é que a mesma ocorre em âmbito global e ao longo de uma cadeia complexa, que parte do campo, ou seja, da produção dos alimentos até o ponto de consumo, como domicílios e unidades de alimentação. No entanto, os padrões de perda

\footnotetext{
${ }^{*}$ UFRGS Campus Litoral Norte - Engenheiro Ambiental e mestre em Engenharia de Processos e Tecnologias. ${ }^{* *}$ UFRGS Campus Litoral Norte - Licenciada em Filosofia, mestre em Filosofia e Doutora em Filosofia.

${ }^{* * *}$ UCS - Nutricionista, mestre em Saúde Coletiva e doutoranda em Saúde Coletiva.
} 
variam de região para região e estão relacionados, principalmente, com os níveis de desenvolvimento socioeconômico. Muitas vezes, a situação é evidenciada como sendo de ordem cultural, e não técnica, podendo a solução ser relativamente simples. Como sugestões de possíveis soluções, podemos destacar a conscientização da população e a adoção de técnicas adequadas de produção, manejo, transporte, processamento, oferta e consumo de alimentos.

Nesse sentido, as ações de educação ambiental são importantes para promover a reflexão da população sobre as suas ações com relação ao desperdício. A legislação brasileira, inclusive, trata da educação ambiental e das responsabilidades que as instituições públicas e privadas, assim como a coletividade têm com o seu cumprimento.

A fim de contribuir com os estudos sobre o tema, o objetivo desse trabalho foi realizar uma investigação sobre o desperdício de alimentos por famílias de um bairro do município de classe média de Caxias do Sul/RS, coletando informações sobre padrões de consumo e descarte de alimentos.

\section{Fundamentação Teórica}

2.1 O desperdício de alimentos e suas implicações

As projeções indicam que em 2075 a população mundial pode chegar a 9,5 bilhões de pessoas, o que significa um aumento de três bilhões de pessoas buscando alimentos para o seu sustento. Atualmente são produzidos em torno de 4 bilhões de toneladas de alimentos por ano, porém, estima-se que entre $30-50 \%$ de toda a comida produzida no mundo (1,2-2 bilhões de toneladas) seja transformada em resíduo sólido. Portanto, políticas sociais, econômicas e ambientais precisam ser estabelecidas hoje para garantir a sustentabilidade no futuro (IMECHE, 2013).

Resíduo sólido é definido como:

material, substância, objeto ou bem descartado resultante de atividades humanas em sociedade, cuja destinação final se procede, se propõe proceder ou se está obrigado a proceder, nos estados sólido ou semi-sólido, bem como gases contidos em recipientes e líquidos cujas particularidades tornem inviável o seu lançamento na rede pública de esgotos ou em corpos d'água, ou exijam para isso soluções técnica ou economicamente inviáveis em face da melhor tecnologia disponível. (BRASIL, 2010). 
Contudo, o manejo, o transporte, o tratamento e a destinação final dos resíduos sólidos envolvem o dispêndio de recursos públicos e privados que poderiam ser evitados ou minimizados.

Examinando o Decreto-lei $n^{\circ} 38.356$, que aprova o regulamento da Lei $n^{\circ} 9.921$ de 27 de julho de 1993, que dispõe sobre a gestão dos resíduos sólidos no Estado do Rio Grande do Sul (RIO GRANDE DO SUL, 1998), é possível identificar o compromisso que todos os

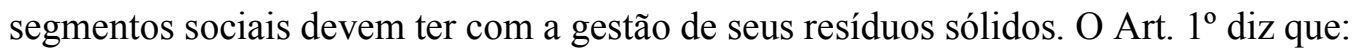

a gestão dos resíduos sólidos é responsabilidade de toda a sociedade e deverá ter como meta prioritária a sua não geração, devendo o sistema de gerenciamento destes resíduos buscar sua minimização, reutilização, reciclagem, tratamento ou destinação adequada.

A meta de não geração também é destacada como um dos objetivos da Política Nacional de Resíduos Sólidos (BRASIL, 2010).

Legaspe (2005) salienta que os resíduos são uma fonte de riqueza, possuindo uma enorme possibilidade de uso. Ele afirma que "[...] ao enterrarmos nos aterros sanitários e lixões milhares de toneladas de matérias-primas, estamos reforçando a lógica do consumo na sua atitude mais voraz, que é a de destruir para fortalecer o sistema econômico atual.” (p. 4.190). O autor destaca que a sociedade deve visualizar nos resíduos uma fonte de recursos a ser explorada.

As ações que tem por objetivo minimizar a geração de resíduos sólidos, entre elas, os resíduos alimentares, podem trazer diversos benefícios: redução de custos com manejo, transporte, tratamento e disposição final dos resíduos; redução do espaço para armazenamento de resíduos, o qual pode ser utilizado para fins de maior utilidade; redução de custos de produção ao se utilizar menos insumos e energia; redução dos riscos relacionados ao manejo dos resíduos; minimização dos impactos ambientais dos empreendimentos; e melhoria da imagem das instituições (CRITTENDEN; KOLACZKOWSKI, 1995).

De acordo com relatório divulgado pelo Instituto dos Engenheiros Mecânicos (IMECHE, 2013), o desperdício de alimentos deve receber atenção especial pelos danos diretos e indiretos causados à sociedade e à natureza, como, por exemplo, o uso de grandes extensões de terra, energia, fertilizantes e água, recursos que também são perdidos quando alimentos são desperdiçados.

Em decorrência dessa grave situação, o tema é atualmente um dos pilares do Plano de Ação da Comunidade de Estados Latino-Americanos e Caribenhos (CELAC) 2025 para a Segurança Alimentar, Nutrição e Erradicação da Fome (CELAC, 2016), o que reforça a 
importância de se discutir o tema e propor políticas públicas de combate ao desperdício de alimentos. O Conselho Nacional de Segurança Alimentar e Nutricional (CONSEA, 2015) reforça que os aspectos ligados à produção e consumo de alimentos são primordiais para a garantia da Segurança Alimentar e Nutricional (SAN).

Bastos (2015) destaca a preocupação atual no combate ao desperdício de alimentos. Na Oficina "Redução de Perdas e Desperdícios e Segurança Alimentar e Nutricional" promovida pela Embrapa em 2015, a qual reuniu agentes de instituições públicas, privadas e do terceiro setor, os participantes apontaram a necessidade de elaborar um diagnóstico sobre as perdas e desperdício de alimentos no Brasil, com o intuito de propor novas políticas públicas. Além disso, os participantes citaram a promoção do aproveitamento integral dos alimentos, inclusive daqueles fora do padrão comercial, capacitações de produtores acerca de boas práticas de manipulação e transporte de alimentos, e utilização de restos de alimentos em sistemas de compostagem.

O $2^{\circ}$ Plano Nacional de Segurança Alimentar e Nutricional (BRASIL, 2016), elaborado pela Câmara Interministerial de Segurança Alimentar e Nutricional (CAISAN), apresenta entre os seus desafios, por exemplo, a promoção do abastecimento regular e permanente da população brasileira à alimentação adequada e saudável. Ao detalhar esse último desafio, o plano cita algumas medidas de combate ao desperdício de alimentos, embora não específicas para domicílios.

Os motivos que levam ao desperdício de alimentos são diversos: perdas na lavoura em razão de técnicas de agricultura, estocagem e transporte inadequados; métodos de conservação de alimentos defasados ou ineficientes; distância de centros urbanos - o que dificulta a aquisição de alimentos frescos; perdas no varejo; características do consumidor atual, ou seja, que seleciona os alimentos por padrões estéticos; e promoções que estimulam consumidores a comprar mais do que precisam. De acordo com o relatório, em países desenvolvidos, o desperdício está mais relacionado a aspectos políticos, econômicos e de comportamento da sociedade, sendo as perdas concentradas ao final da cadeia produtiva varejo e domicílios. Nos países em desenvolvimento, as perdas ocorrem com mais intensidade no início da cadeia - na lavoura, transporte e estocagem (KOSSEVA, 2013; IMECHE, 2013; FAO, 2013).

Uma estimativa da geração de resíduos alimentares ao longo da cadeia, em termos mássicos, é apresentada pela Food and Agriculture Organization of the United Nations (FAO, 2013), conforme mostra a Figura 1. 
Figura 1 - Desperdício de alimentos ao longo da cadeia no mundo em um ano.

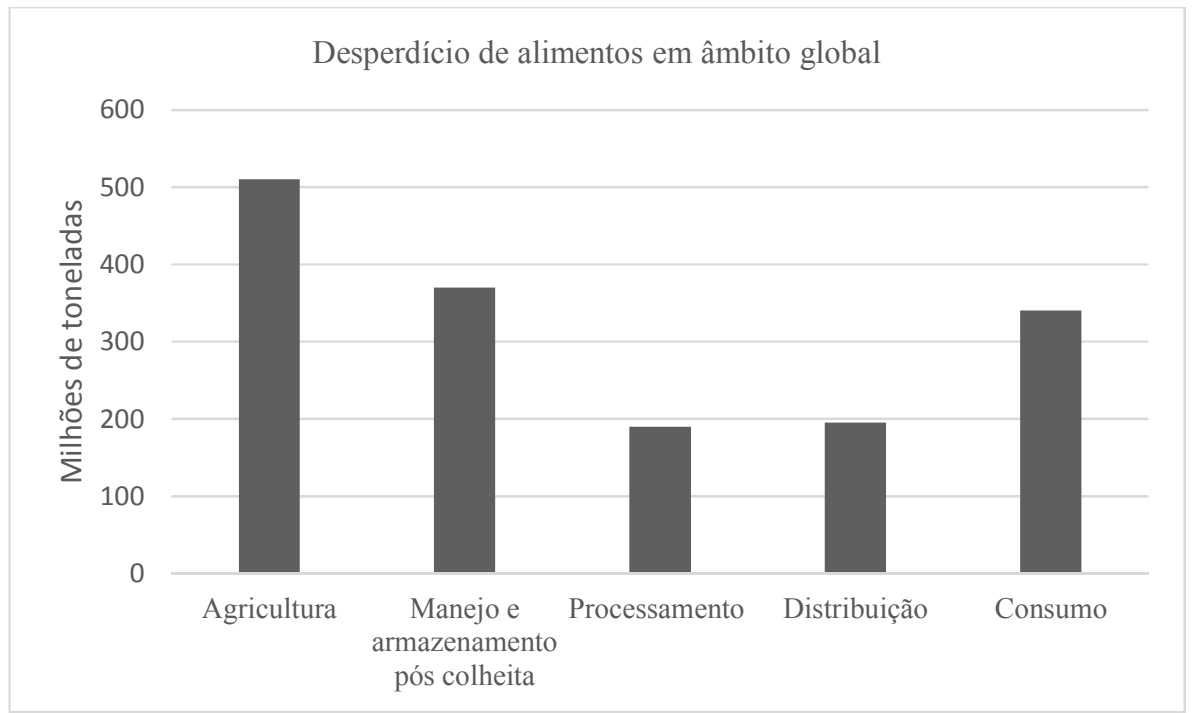

Fonte - Adaptado pelos autores de FAO (2013)

Em termos de emissões de carbono relacionadas ao desperdício de alimentos, os maiores responsáveis são a Europa, Estados Unidos e Ásia industrializada. A América Latina tem uma contribuição um pouco maior que a média mundial, portanto, não se destacando positivamente no ranking (FAO, 2013).

Uma pesquisa realizada por Sonnino e McWilliam (2011) em três hospitais do País de Gales, diagnosticou que uma quantidade muito grande de alimentos era preparada para o número de pacientes atendidos, havendo ainda o preparo de alimentos para pacientes que não tinham refeições nos hospitais. De acordo com os autores, isso ocorre, por exemplo, por falta de capacitação dos colaboradores das instituições pesquisadas e também pela percepção que se tem de que a qualidade dos serviços prestados está relacionada à quantidade de alimentos oferecidos. No que se refere ao desperdício no prato, ficou evidente a falta de atenção dos colaboradores em ofertar alimentos ao gosto dos pacientes. Porções em quantidades préestabelecidas e oferta automática de verduras e legumes contribuíam para aumentar o desperdício. Finalmente, os resultados indicaram que o desperdício de alimentos nos hospitais variou de 19 a 66\%. Os maiores desperdícios foram constatados em refeições ofertadas a pessoas idosas, com porcentagens de desperdício que ultrapassavam $30 \%$ do total de alimentos oferecidos. Em um dos hospitais, por exemplo, para cada $265 \mathrm{~g}$ de alimentos servidos, em média $103 \mathrm{~g}$ foram deixados no prato pelos pacientes. 
Resultados semelhantes são sinalizados por Barton et al. (2000), em um estudo realizado em um hospital universitário. Ao investigarem a causa da perda de peso de pacientes, os pesquisadores surpreenderam-se ao diagnosticar que não havia limitação nutricional de calorias nas refeições servidas, havendo ainda um desperdício de alimentos acima de $40 \%$. Como consequência, a ingestão de calorias e proteínas abaixo dos níveis recomendados colaborava para a contínua perda de peso dos pacientes.

Katajajuuri et al. (2014) mapearam a quantidade e a composição dos resíduos de alimentos gerados na Finlândia, não considerando cascas, borra de café e ossos. Os resultados foram obtidos de pesquisa realizada em 420 domicílios, 72 restaurantes, informações de empresas do varejo e indústria e pesquisas da literatura. No âmbito doméstico, obteve-se uma geração de resíduos de alimentos de aproximadamente 130 milhões de $\mathrm{kg}$ de resíduos de comida/ano, o que representa um desperdício de $23 \mathrm{~kg}$ per capita/ano. Nesse caso, a maior parte dos alimentos descartados são representados por alimentos frescos e perecíveis, ou sobras de preparações e refeições. Essa geração, convertida em gases do efeito estufa, representa, de acordo com cálculos dos autores, a emissão anual de dióxido de carbono de aproximadamente 100.000 carros. Também representaria uma perda de $€ 70,00$ per capita/ano. No setor de serviços de alimentação, a quantidade de resíduos alimentares variou de 7 a $28 \%$ dos alimentos preparados, faixa que depende do tipo de restaurante. Nesse setor, estima-se um desperdício de alimentos que varia entre 75 a 85 milhões de kg/ano. $\mathrm{Na}$ indústria e no varejo, estima-se um desperdício adicional de 75-140 e 65-75 milhões de $\mathrm{kg} / \mathrm{ano}$, respectivamente. Portanto, o desperdício de alimentos total na Finlândia, é estimado em 335-460 milhões de kg/ano. É importante salientar que esses números não consideram o que é perdido ainda na produção primária.

Não considerando as perdas na produção primária, dados da European Commission (2010) também indicam que os domicílios são grandes geradores de resíduos alimentares, conforme ilustra a Figura 2 (EUROPEAN COMMISSION, 2010). 
Figura 2 - Proporção de descarte de alimentos ao longo da cadeia na Europa.

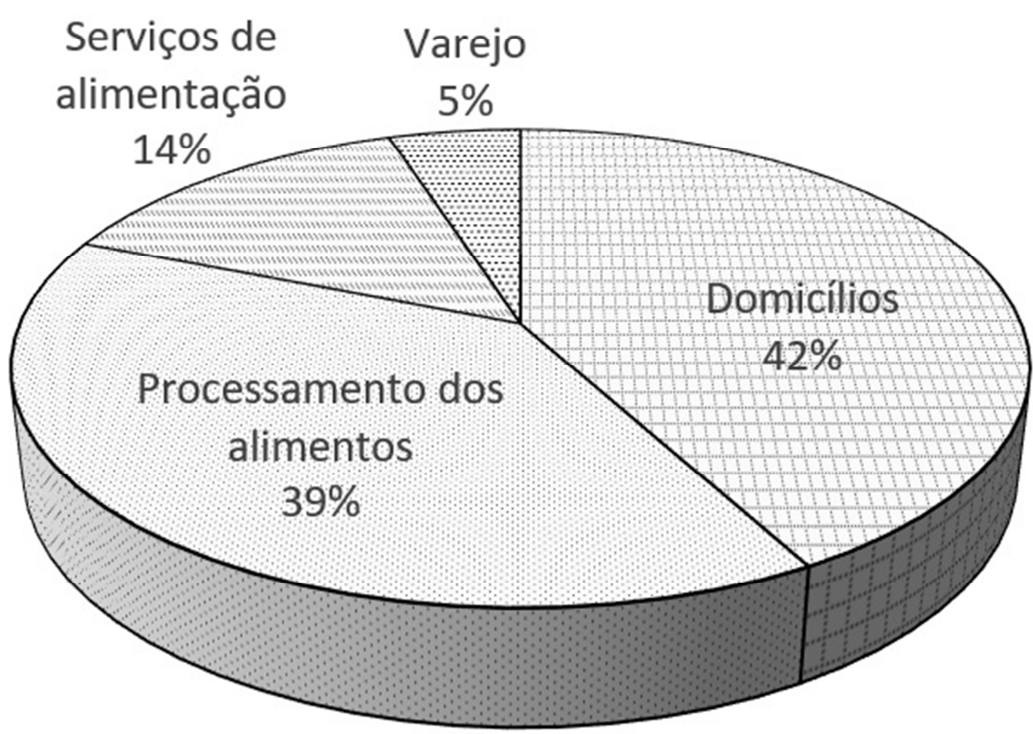

Fonte - Adaptado pelos autores de European Commission (2010)

Ao avaliarem a geração de resíduos de alimentos em 4.854 estabelecimentos do Havaí, com alguma ligação com o ramo da alimentação, Okazaki, Turn e Flachsbart (2008) constataram que $45 \%$ enviavam os resíduos de alimentos para disposição final em aterro, $25 \%$ indicaram não gerar resíduos alimentares em suas operações, $22 \%$ promoviam a reciclagem desse material (ex. alimentação de animais e doações para bancos de alimentos) e $8 \%$ reciclavam e também enviavam para disposição final os resíduos alimentares gerados. Entre as categorias de estabelecimentos geradores de resíduos alimentares, a mais representativa em termos de produção era a de restaurantes. Entre os estabelecimentos pesquisados, que indicaram não promover a reciclagem dos resíduos alimentares, diversas razões foram apontadas pelos dirigentes: a separação dos resíduos alimentares de outros resíduos consome muito tempo ou envolve custos; dificuldades de armazenamento, transporte e logística; problemas do ponto de vista sanitário e de saúde; não geração ou pequena geração de resíduos alimentares; desconhecimento que os resíduos alimentares poderiam ser reciclados; falta de oportunidade para reciclar; não ter permissão para adotar práticas de reciclagem de resíduos alimentares. Finalmente, foi estimado que a geração de resíduos alimentares no Havaí é de aproximadamente 336,5 toneladas anuais ou $0,66 \mathrm{~kg} / \mathrm{pessoa} / \mathrm{dia}$. 


\section{\#tear}

Sobre a geração de resíduos alimentares em restaurantes, são importantes as contribuições de Pistorello, De Conto e Zaro (2015) que realizaram um balanço mássico do café da manhã de um restaurante de um meio de hospedagem de Caxias do Sul/RS. O balanço mássico refere-se ao processo que envolve a segregação de resíduos por categorias, e posterior pesagem, para determinação da representatividade das diferentes tipologias de materiais no montante de resíduos gerados. A pesquisa obteve que, do total de alimentos ofertados aos hóspedes, apenas 37,3\% eram consumidos, 49,2\% eram intocados e 13,5\% correspondiam a resíduos gerados pelos hóspedes. Além disso, do total de alimentos utilizados no preparo do café da manhã, $21,3 \%$ eram transformados em resíduos ainda no processamento dos alimentos na cozinha. A Figura 3 apresenta os resultados da pesquisa. Concluiu-se que, em muitas situações, o desperdício de alimentos no restaurante ocorria devido à oferta de alimentos ser maior do que o consumo pelos clientes. Constatou-se a necessidade de promover uma readequação do planejamento realizado no restaurante, buscando reduzir a disparidade observada. Relatos de alguns colaboradores do meio de hospedagem indicaram que a quantidade de alimentos ofertados é um indício da qualidade do restaurante e dos serviços do meio de hospedagem.

Figura 3 - Balanço mássico de um restaurante de meio de hospedagem de Caxias do Sul

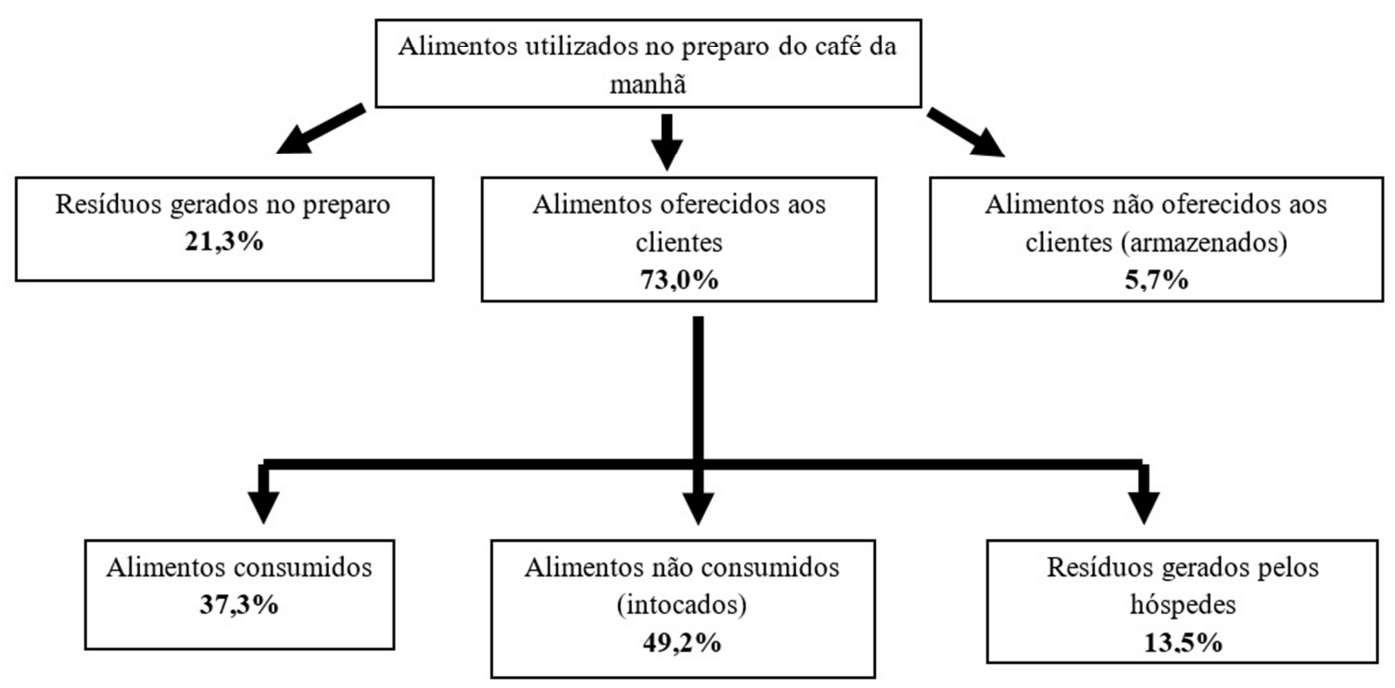

Fonte - Adaptado pelos autores de Pistorello, De Conto e Zaro (2015) 
Nonenmacher e Kalsing (2012) destacam resultados de um balanço mássico realizado por alunos no refeitório do Instituto Federal Catarinense - Campus Concórdia/SC, referentes à pesagem dos resíduos alimentares gerados durante cinco dias - não contabilizando os ossos. $\mathrm{Na}$ semana de amostragem, foram servidas 1.964 refeições, sendo que em 419 delas foi constatado o desperdício de alimentos. Em termos mássicos, foram fornecidos 1.500,28 kg de alimentos, sendo $281,50 \mathrm{~kg}(18,8 \%)$ referentes à alimentos não consumidos.

Diante desse contexto, são importantes as ações e/ou programas de redução de desperdício de alimentos que, para serem completos e efetivos, devem combinar mudanças comportamentais, educação e, principalmente, sensibilização conjunta de consumidores, produtores e manipuladores de alimentos (BRADACZ, 2003).

Santos (2004, p. 158) incita uma reflexão entre a relação da participação pública e educação no planejamento ambiental. De acordo com a autora, o processo de planejamento ambiental somente é efetivo quando há participação pública nos diversos momentos de seu processamento. E, nesse contexto, educação e participação estão interligados. Participar de um planejamento envolve tomar parte, integrando-se pela razão e sentimento, fazer saber, saber comunicar, identificar interesses, expectativas e valores, observar analogias, argumentar, evidenciar pontos comuns, definir interesses, fomentar alianças, fazer ajustes e tomar decisões de entendimento comum sobre o que for de uso ou do direito coletivo. A busca de soluções para um determinado problema envolve um processo que visa verificar, discutir e estimular possibilidades de mudanças de hábitos, comportamentos, conceitos e práticas diárias, sem esquecer os contextos político, econômico, ambiental, cultural e social dos grupos envolvidos.

Quando se trata do emprego de programas de educação ambiental como mecanismo de combate ao desperdício de alimentos, é importante destacar a Lei no 9.795 de 1999 (BRASIL, 1999), que dispõe sobre a Política Nacional de Educação Ambiental. O Art. $1^{\text {o define a }}$ educação ambiental como:

os processos por meio dos quais o indivíduo e a coletividade constroem valores sociais, conhecimentos, habilidades, atitudes e competências voltadas para a conservação do meio ambiente, bem de uso comum do povo, essencial à sadia qualidade de vida e sua sustentabilidade.

A partir do Art. $3^{\text {o }}$ é possível constatar a responsabilidade pela incorporação da dimensão ambiental na gestão das organizações. Todos os segmentos da sociedade precisam conhecer a Política Nacional de Educação Ambiental e assumir o seu papel no cumprimento da mesma. 
Considerando que a informação é uma variável que determina o comportamento das pessoas em relação ao meio ambiente, Mandelli (1997) destaca que a mesma deve ser de qualidade e disponibilizada de forma contínua à população.

Sendo que os efeitos negativos do desperdício de alimentos atingem a todos, é importante que ainda se aponte a Constituição Federal de 1988 (BRASIL, 1988), em seu capítulo VI, Art. 225:

Todos têm direito ao meio ambiente ecologicamente equilibrado, bem de uso comum do povo e essencial à sadia qualidade de vida, impondo-se ao Poder Público e à coletividade o dever de defendê-lo e preservá-lo para as presentes e futuras gerações.

A partir do estudo bibliográfico, é possível inferir que o desperdício de alimentos, e consequente geração de impactos ambientais, exige uma abordagem multidisciplinar e imediata, envolvendo diversas áreas do conhecimento.

\section{Materiais e métodos}

A técnica de pesquisa utilizada foi a observação direta extensiva, tendo como instrumento de coleta de dados o questionário (MARCONI; LAKATOS, 2011). O questionário foi elaborado com perguntas abertas, fechadas e de múltipla escolha, e após efetuado o pré-teste com três indivíduos não participantes da pesquisa. A partir dos resultados dos pré-testes, foram feitas as alterações pertinentes.

O questionário foi escolhido como instrumento de pesquisa, pois como indica Marconi e Lakatos (2011), esse apresenta diversas vantagens, tais como, economia de tempo e viagens; permite obter grande número de dados; atinge um número maior de indivíduos simultaneamente; abrange uma área geográfica ampla; e permite maior liberdade nas respostas, decorrente do anonimato. Embora o questionário apresente diversos aspectos positivos, a elaboração do questionário é uma etapa crítica, que requer muita atenção por parte do pesquisador, de modo a evitar a indução de respostas.

Um total de 220 questionários foram entregues a estudantes de uma escola municipal de Caxias do Sul/RS e solicitado que os mesmos entregassem o material aos pais, para que assim fizessem o seu preenchimento. Anexadas aos questionários, foram enviadas cartas com uma breve apresentação da pesquisa e sua importância, e instruções de preenchimento. A coleta dos questionários foi feita através dos estudantes alguns dias após a entrega. O bairro foi selecionado, pois na escola local seria realizado um projeto de sensibilização com a comunidade escolar sobre o tema desperdício de alimentos. Segundo o Censo de 2010, a 


\section{\#tear}

população do bairro era de 5.672 habitantes (IBGE, 2010). A Figura 4 apresenta a localização do bairro São José no município de Caxias do Sul, não distante da área central. Não há dados socioambientais sobre a região, porém, é um bairro notoriamente de classe média.

Figura 4 - Localização do bairro São José na área urbana de Caxias do Sul

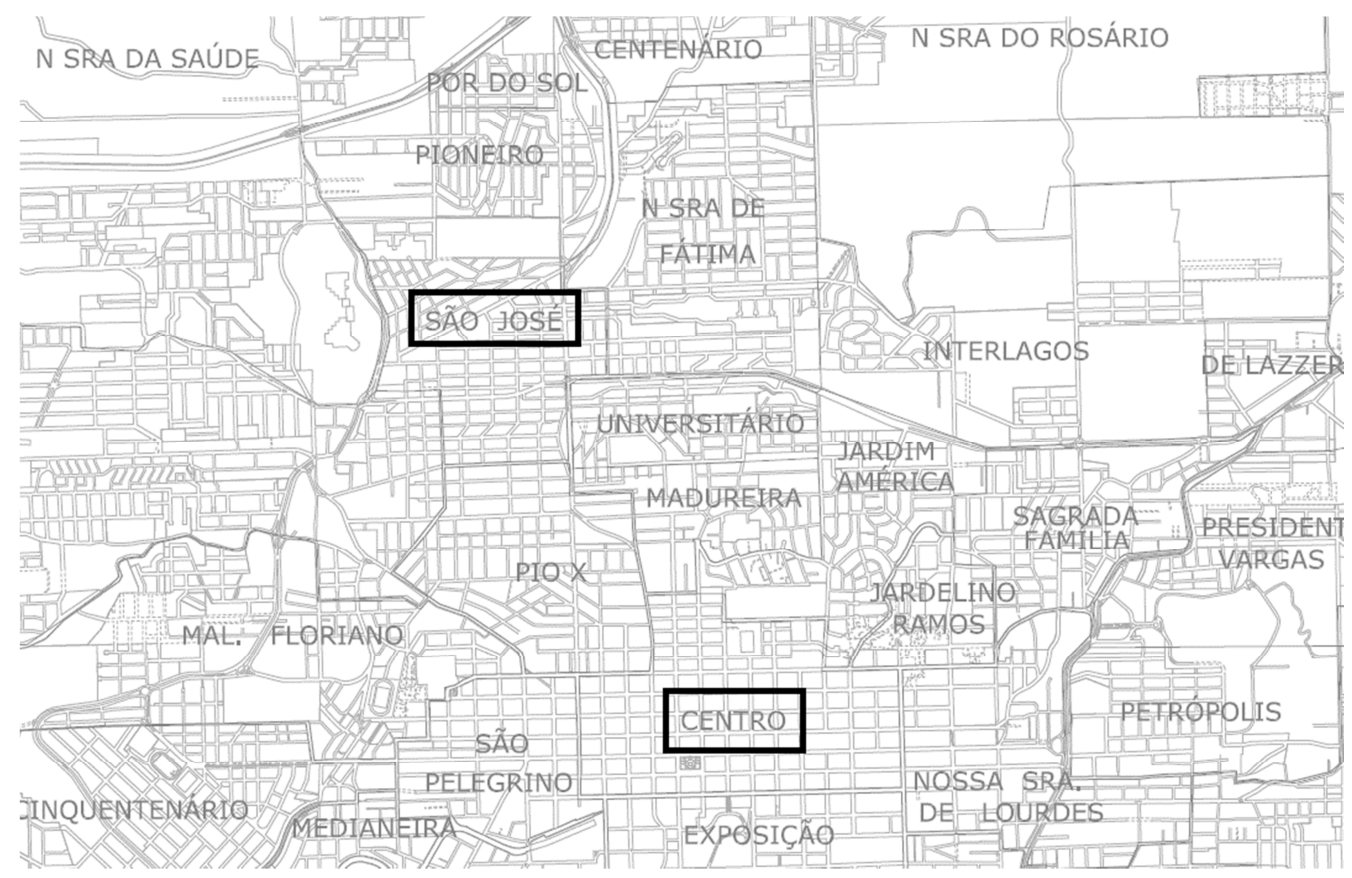

Fonte - Prefeitura Municipal de Caxias do Sul (2010)

O questionário continha perguntas sobre: o número de integrantes do grupo familiar; frequência que realizavam a compra de alimentos; se elaboravam lista de compras e se compravam além do previsto na lista; se observavam e aproveitavam promoções para adquirirem produtos; se pesquisavam a validade dos produtos adquiridos; se percebiam o desperdício de alimentos em casa; destinação dada aos resíduos sólidos alimentares gerados; e que hábitos de compra poderiam adotar para evitar o desperdício de alimentos.

\section{Resultados e discussão}

A Tabela 1 apresenta o número de questionários entregues e devolvidos pelas famílias pesquisadas, obtendo-se um retorno efetivo de 34,5\%. Em média, nesse tipo de pesquisa o retorno é de 25\% (MARCONI; LAKATOS, 2011). 
Tabela 1 - Relação de questionários entregues e devolvidos

\begin{tabular}{ccc}
\hline & $\mathrm{n}$ & $\%$ \\
\hline Questionários não devolvidos & 138 & 62,7 \\
Questionários devolvidos preenchidos & 76 & 34,5 \\
Questionários devolvidos em branco & 6 & 2,7 \\
\hline Total & 220 & 100 \\
\hline Fonte - os autores &
\end{tabular}

De acordo com as informações prestadas nos questionários, 47,4\% das famílias contava com quatro integrantes e $26,3 \%$ com três (Tabela 2 ).

Tabela 2 - Distribuição de frequência e porcentagem de indicações do número de integrantes do grupo familiar

\begin{tabular}{ccc}
\hline Integrantes do grupo familiar & $\mathrm{f}$ & $\%$ \\
\hline 2 & 2 & 2,6 \\
3 & 20 & 26,3 \\
4 & 36 & 47,4 \\
5 & 8 & 10,5 \\
mais de 5 & 10 & 13,2 \\
\hline Total & 76 & 100 \\
\hline \multicolumn{2}{c}{ Fonte - os autores }
\end{tabular}

A Tabela 3 aponta que a maior parte das famílias $(36,8 \%)$ realiza a compra de alimentos semanalmente, resultado similar ao obtido por Stefan et al. (2013) em pesquisa com 268 consumidores romenos $(42 \%)$. Os autores mostraram que o planejamento e rotina de compras se relacionam com o desperdício de alimentos, sendo que compras planejadas tendem a reduzir a suscetibilidade de consumidores adquirirem alimentos em excesso. Portanto, é importante promover ações voltadas à compra consciente de alimentos e difundir as práticas adequadas de armazenamento nos domicílios.

Tabela 3 - Distribuição de frequência e porcentagem de indicações sobre a regularidade que realizam a compra de alimentos

\begin{tabular}{ccc}
\hline Frequência de compra alimentos & $\mathrm{f}$ & $\%$ \\
\hline Semanalmente & 28 & 36,8 \\
Diariamente & 24 & 31,6 \\
Mensalmente & 20 & 26,3 \\
Semanalmente e mensalmente & 2 & 2,6 \\
Diariamente e mensalmente & 1 & 1,3 \\
Diariamente e semanalmente & 1 & 1,3 \\
\hline Total & 76 & 100 \\
\hline Fonte: os autores & &
\end{tabular}

Uma parcela também importante de famílias indicou realizar a compra de alimentos diariamente $(31,6 \%)$ ou mensalmente $(26,3 \%)$. Durante a pesquisa, surgiram questionários 
com mais de uma opção assinalada, o que gerou três novas categorias de respostas na organização dos resultados em tabela.

As compras realizadas diariamente possuem como vantagem a aquisição de produtos frescos ou distantes da data de expiração da validade, o que se reflete em menos perdas, porém, podem estimular a compra de produtos não planejados e passíveis de serem desperdiçados.

Os dados apresentados na Tabela 4 sinalizam que mais da metade das famílias, ou seja, $56,6 \%$, às vezes elaboram lista de compras, enquanto $31,6 \%$ indicam sempre fazer. Porém, 36,8\% afirmam comprar além do planejado na lista, e 43,4\% indicam que essa situação ocorre às vezes. Os indivíduos que responderam comprar ou às vezes comprar além do planejado na lista foram solicitados a indicar livremente exemplos de produtos adquiridos. As principais respostas foram categorizadas e apresentadas na Tabela 5. Dos 46 questionários que continham informações, é possível constatar que doces, bolachas, refrigerantes e salgadinhos destacam-se entre os produtos adquiridos além do previsto, assim como "itens vistos na hora" e produtos em oferta/promoção.

Em pesquisa realizada no Reino Unido, $58 \%$ dos consumidores informaram que na maioria das vezes planejam as suas compras com o uso de listas. No entanto, $19 \%$ informaram nunca usar listas. Foi constatado que o fator idade está relacionado ao uso de listas nas compras, sendo o público jovem menos propenso à sua adoção. A lista, em geral, é escrita, mas algumas vezes mentalizada. Apenas $26 \%$ dos consumidores informaram raramente ou nunca comprar além do planejado. Finalmente, aproximadamente $39 \%$ das compras são referentes a itens não planejados (WRAP, 2007).

Tabela 4 - Distribuição de frequência e porcentagem de indicações sobre a elaboração de lista de compras e sobre comprar mais do que o planejado na lista

\begin{tabular}{ccc}
\hline Elaboração de lista de compras & $\mathrm{f}$ & $\%$ \\
\hline Às vezes & 43 & 56,6 \\
Sim & 24 & 31,6 \\
Não & 9 & 11,8 \\
\hline Total & 76 & 100 \\
\hline Compra além do planejado na lista & $\mathrm{f}$ & $\%$ \\
\hline Às vezes & 33 & 43,4 \\
Sim & 28 & 36,8 \\
Não & 10 & 13,2 \\
Não respondeu & 5 & 6,6 \\
\hline Total & 76 & 100 \\
\hline Fonte - os autores &
\end{tabular}




\section{\#tear \\ Revista de Educaçăo, Ciência e Tecnologia}

Tabela 5 - Frequência de indicações dos indivíduos que responderam adquirir ou às vezes adquirir itens além do que está na lista sobre os produtos adquiridos além do planejado

\begin{tabular}{cc}
\hline Produtos adquiridos além do planejado & $\mathrm{f}$ \\
\hline Produtos em oferta/promoção & 10 \\
Doces & 9 \\
Chocolate & 7 \\
Bolachas/biscoitos & 7 \\
Itens vistos na hora & 7 \\
Salgadinhos & 6 \\
Refrigerante & 4 \\
Frutas, verduras e legumes & 3 \\
Balas & 3 \\
Produtos de limpeza & 3 \\
Guloseimas & 2 \\
Salgados & 2 \\
Pirulito & 1 \\
Iogurte & 1 \\
"Besteiras" & 1 \\
Bolacha recheada & 1 \\
Novidades & 1 \\
Sorvete & 1 \\
Carnes & 1 \\
\hline Total & 68 \\
\hline Fonte - os autores &
\end{tabular}

Os dados da Tabela 6 mostram que a grande maioria das famílias $(71,1 \%)$ observam promoções em estabelecimentos comerciais e aproveitam para realizar a compra de alimentos $(59,2 \%)$. Apesar do risco de se adquirirem produtos cuja validade expira em pouco tempo, como é comum acontecer em promoções, $86,8 \%$ dos respondentes informaram verificar o prazo da validade dos produtos (Tabela 7).

Tabela 6 - Distribuição de frequência e porcentagem de indicações sobre observar e aproveitar promoções para realizar a compra de alimentos em estabelecimentos comerciais

\begin{tabular}{ccc}
\hline Observa promoções & $\mathrm{f}$ & $\%$ \\
\hline Sim & 54 & 71,1 \\
Às vezes & 16 & 21,1 \\
Não & 6 & 7,9 \\
\hline Total & 76 & 100 \\
\hline Aproveita para comprar alimentos em & $\mathrm{f}$ & $\%$ \\
promoções & 45 & 59,2 \\
Sim & 26 & 34,2 \\
Às vezes & 5 & 6,6 \\
Não & 76 & 100 \\
\hline Total &
\end{tabular}


Tabela 7 - Distribuição de frequência e porcentagem de indicações sobre pesquisar a data de validade dos produtos

\begin{tabular}{ccc}
\hline Pesquisa a data de validade dos produtos & $\mathrm{f}$ & $\%$ \\
\hline Sim & 66 & 86,8 \\
Às vezes & 8 & 10,5 \\
Não & 2 & 2,6 \\
\hline Total & 76 & 100 \\
\hline & Fonte - os autores
\end{tabular}

Sobre o desperdício de alimentos no âmbito domiciliar, 42,1\% dos respondentes afirmaram que essa situação ocorre em suas casas, e um percentual menor de respondentes $(28,9 \%)$ que não há desperdício de alimentos em seus domicílios (Tabela 8).

Tabela 8 - Distribuição de frequência e porcentagem de indicações sobre perceber o desperdício de alimentos em casa

\begin{tabular}{ccc}
\hline Percebe o desperdício de alimentos em casa & $\mathrm{f}$ & $\%$ \\
\hline Sim & 32 & 42,1 \\
Não & 22 & 28,9 \\
Às vezes & 22 & 28,9 \\
\hline Total & 76 & 100 \\
\hline Fonte - os autores &
\end{tabular}

Quando solicitados a dar exemplos de como o desperdício ocorre nas suas residências, 18 dos 36 indivíduos que deixaram informações a respeito nos questionários indicaram claramente as refeições como principal origem do desperdício em casa. Frutas estragadas (6 indicações), arroz (5 indicações) e pão (3 indicações) são exemplos de itens desperdiçados apontados nos questionários. Stefan et al. (2013) sinalizam que a adoção de boas práticas relacionadas ao preparo das refeições ajudaria a realizar um balanço adequado entre a quantidade alimentos preparados e consumidos, resultando na redução da geração de resíduos de alimentares.

Williams et al. (2012) relatam diversas razões que levam ao desperdício de alimentos em pesquisa com 61 famílias da Suécia. No estudo, as famílias foram convidadas a observar a sua geração de resíduos e responder a um questionário sobre os seus padrões de descarte. Ambos os grupos indicaram que aproximadamente $50 \%$ da comida era descartada por ter estragado e, em torno de $25 \%$, porque foi preparada em uma quantidade maior que a consumida. O tamanho de embalagens e a dificuldade em se esvaziar algumas delas, devido ao seu design, também foram relatadas pelos respondentes como motivos para terem desperdiçado alimentos.

Stancu, Haugaard e Lahteenmaki (2016) relatam, além de rotinas domésticas (ex. planejamento, compras e reuso de sobras), outros fatores que influenciam no desperdício de alimentos. Informações de 1.062 respondentes dinamarqueses demonstraram, por exemplo, 
um menor desperdício de alimentos entre famílias menos numerosas, consumidores mais idosos e indivíduos de menor renda, o que também denota aspectos culturais e econômicos.

Embora muitas vezes o desperdício esteja popularmente associado ao maior poder aquisitivo das famílias, a pesquisa de Porpino, Parente e Wansink (2015) com 14 famílias brasileiras de menor renda demonstrou que o fenômeno "desperdício de alimentos", coexiste em grupos com perfis socioeconômicos diferentes. Os pesquisadores identificaram diversos motivos que levam às perdas de alimentos pelos consumidores, tais como: a) compra excessiva motivada por impulsividade, falta de planejamento nas compras, preferência por embalagens maiores, promoções e preferência por marcas específicas; b) excesso no preparo em razão de senso de hospitalidade e sentimento de abundância, falta de planejamento ou habilidade no preparo das refeições; c) animais de estimação que "justificam” o excesso, bem como senso de cuidado; d) preconceito com sobras, havendo preferência por alimentos frescos; e e) práticas deficitárias de conservação de alimentos, como o seu não armazenamento sob refrigeração adequada.

As famílias foram solicitadas a indicar o destino dado aos resíduos de alimentos, podendo mais de uma alternativa ser assinalada (Tabela 9). O número de indicações mais representativo aponta o reaproveitamento dos alimentos em outras refeições (46) e destinação dos resíduos à coleta pública (40). A alimentação de animais por restos de alimentos também foi apontada (34). A reduzida frequência de indicações sobre a existência de uma composteira caseira (12) indica que a compostagem é uma técnica ainda pouco difundida entre as famílias.

Dias, Martinez e Barros (2014), com base em projeções da geração de resíduos sólidos urbanos no município do Rio de Janeiro/RJ, sinalizam que a ampliação e aumento da eficiência dos serviços de limpeza não podem acontecer, por exemplo, sem o aumento da reciclagem. Deste modo, pode-se afirmar que a compostagem poderia auxiliar na minimização da geração de resíduos sólidos que são coletados e transportados pela municipalidade até o aterro sanitário.

Tabela 9 - Distribuição de frequência de indicações sobre o destino dado aos resíduos de alimentos

\begin{tabular}{cc}
\hline Destino dos resíduos alimentares & $\mathrm{f}$ \\
\hline Reaproveita em outras refeições & 46 \\
Destinados à coleta pública & 40 \\
Alimentação de animais & 34 \\
Não há desperdício & 13 \\
Composteira caseira & 12 \\
Doados & 4 \\
Total & 149 \\
\hline Fonte - os autores
\end{tabular}


A última pergunta, referente às ações que poderiam ser tomadas a fim de evitar o desperdício de alimentos durante a compra, foi livre, e teve o intuito de avaliar o conhecimento das famílias e coletar informações adicionais sobre o assunto. A pergunta foi respondida por 64 sujeitos $(84,2 \%)$. Foi constatado, a partir da análise das informações, que apenas 2 indivíduos discorreram quanto ao cuidado de se prestar atenção no prazo de validade dos produtos adquiridos, embora $86,8 \%$ tenham previamente indicado pesquisar. Outra ação importante, que se refere ao cuidado na seleção de frutas e verduras, foi apontada por somente 1 sujeito. A importância da lista no planejamento das compras, citada no questionário, foi destacada por 10 indivíduos. No entanto, a maioria dos respondentes indicou o cuidado em se adquirir apenas o necessário, conforme exemplos de informações deixadas pelos respondentes nos questionários, apresentados no Quadro 1.

Quadro 1 - Transcrições diretas de ações que poderiam ser tomadas a fím de evitar o desperdício de alimentos durante a compra, de acordo com as informações prestadas nos questionários

\begin{tabular}{|c|c|}
\hline Sujeito A & "Comprar apenas o necessário." \\
\hline Sujeito B & "Comprar somente o que vai ser utilizado." \\
\hline Sujeito C & "Evitar comprar alguns alimentos em excesso." \\
\hline Sujeito D & "Comprar em menor quantidade e cozinhar também." \\
\hline Sujeito E & "Ver realmente o que necessita, fazendo lista de compras." \\
\hline Sujeito F & "Comprar só o necessário para não sobrar." \\
\hline Sujeito G & "Comprar só o que é necessário para não jogar no lixo". \\
\hline Sujeito H & "Quantidades menores de frutas e legumes." \\
\hline
\end{tabular}

Fonte - os autores

\section{Conclusões}

A partir do estudo bibliográfico e dos resultados obtidos nessa pesquisa, é possível inferir que o desperdício de alimentos é um problema que perpassa fronteiras, e que requer atenção imediata a fim de minimizá-lo.

Os grupos familiares que realizam compras diariamente têm a tendência de adquirirem produtos mais frescos e distantes da data de expiração da validade, porém, ficam mais vulneráveis a aquisições movidas por impulso, incluindo guloseimas. A compra de itens em promoção, indicada pela maioria dos respondentes, também pode favorecer o ato da compra sem planejamento. Por outro lado, a aquisição de itens em promoção pode ser salutar em termos financeiros, embora deva haver atenção para que não ocorram perdas dentro de casa devido ao não consumo desses bens.

A indicação que mais da metade das famílias às vezes elaboram listas antes de irem às compras mostra um potencial para ações educativas nos moldes da Política Nacional de 


\title{
\#tear
}

Educação Ambiental quanto à importância do planejamento das mesmas, principalmente porque grande parte dos entrevistados destacaram adquirirem ou às vezes adquirirem mercadorias além do programado.

Quando o descarte de alimentos for inevitável, técnicas de compostagem são uma ótima solução do ponto de vista econômico e sanitário, reduzindo a quantidade de resíduos dispostos em vias públicas, os custos com transporte, armazenamento temporário, tratamento e disposição final desses materiais, a poluição visual, a geração de gases do efeito estufa, a atração de vetores, entre outros.

Constatou-se também uma limitação de informações da população sobre o tema, pois foram apresentadas poucas ações que poderiam ser tomadas pelos consumidores para evitar o desperdício de alimentos durante as compras. Uma possível explicação pode ser a pouca atenção dada ao assunto até então e uma carência em termos de programas de conscientização. Assim, há espaço para ações multidisciplinares de sensibilização da comunidade, que deve ser informada e preparada para compreender os efeitos do desperdício de alimentos no meio ambiente e economia e, consequentemente, no seu cotidiano.

O planejamento das compras e o seu adequado armazenamento nos pontos de processamento e consumo, o aproveitamento integral de alimentos e o próprio descarte, por exemplo, são assuntos que podem facilmente ser discutidos com a população, exigindo, para tal, mais capital humano do que financeiro. O próprio questionário entregue às famílias pode ser considerado um instrumento que instiga o autoquestionamento da realidade a qual se está inserido.

Vislumbra-se um estágio em que o próprio indivíduo, ciente da situação, e preparado para agir, se torne um agente disseminador das boas práticas envolvendo o correto gerenciamento de alimentos, e também crítico quanto às ações desenvolvidas (ou não) nos âmbitos privado e público.

\section{CONSUMPTION AND DISPOSAL OF FOOD WASTE IN A COMMUNITY OF CAXIAS DO SUL/RS}

\begin{abstract}
The food wastage presents several negatives aspects with regard to the environmental, economic, social and ethical point of view. The aim of this work was to gather information from families of a neighborhood from Caxias do Sul/RS about their food consumption and waste disposal, using questionnaires. The results indicated that $42.1 \%$ of the respondents notice food wastage at home and $36.8 \%$ buy more than planned during their shopping routines. Referring to the disposal of food waste, the reuse in other meals and the destination to the public collection system are common practices among the families. It was verified a lack of information about food wastage, which is a consequence of the little
\end{abstract}




\section{\#tear}

attention given to the issue so far, and a shortage in terms of awareness programs. The study suggests environmental education actions that are still scarce in Brazil, as well as incentives to the adoption of composting techniques in households.

Keywords: Food wastage. Environmental education. Consumption. Solid waste. Management

\section{Referências}

BARTON, A. D. et al. High food wastage and low nutritional intakes in hospital patients. Clinical Nutrition, v. 19, n. 6, p. 445-449, dez. 2000. Disponível em: $<$ http://www.sciencedirect.com/science/article/pii/S026156140090150X > . Acesso em: $<13$ set. 2013 .

BASTOS, A. Pesquisa identifica fatores de desperdício de alimentos em famílias de baixa renda. Embrapa, 2015. Disponível em: $<$ https://www.embrapa.br/web/mobile /noticias//noticia/3381192/pesquisa-identifica-fatores-de-desperdicio-de-alimentos-em-familias-debaixa-renda $>$. Acesso em: 21 out. 2016.

BRADACZ, Dulce Cléa. Modelo de gestão da qualidade para o controle de desperdício de alimentos em unidades de alimentação e nutrição. 2003. 173 f. Dissertação (Mestrado em Engenharia de Produção) - Universidade Federal de Santa Catarina, Florianópolis, 2003. Disponível em: <http://teses.eps.ufsc.br/resumo.a sp?5020>. Acesso em: 14 ago. 2006.

BRASIL. Lei no 9795, de 27 de abril de 1999. Dispõe sobre a educação ambiental, institui a Política Nacional de Educação Ambiental e dá outras providências. Disponível em: $<$ http://www.planalto.gov.br/ccivil_03/leis/L9795.htm>. Acesso em: 19 dez. 2016.

. Lei $\mathbf{n}^{\circ} \mathbf{1 2 . 3 0 5}$ de 02 agosto de 2010. Institui a Política Nacional de Resíduos Sólidos, altera a Lei no 9.605 de 12 de fevereiro de 1998 e dá outras providências. Disponível em: $<$ http://www.planalto.gov.br/ccivil_03/_ato2007-2010/2010/lei/112305.htm> Acesso em: 19 dez. 2016.

Constituição da República Federativa do Brasil de 1988. Disponível em: $\overline{<\mathrm{http} / / / w w w . p l a n a l t o . g o v . b r / c c i v i l \_03 / c o n s t i t u i c a o / c o n s t i t u i \% C 3 \% A 7 a o . h t m>. ~ A c e s s o ~ e m: ~}$ 30 abr. 2010.

. $2^{\circ}$ Plano Nacional de Segurança Alimentar e Nutricional (PlanSAN 2016-2019). Brasília, DF, 2016. Disponível em: <http:/www4.planalto.gov.br/consea/comunicacao/n oticias/2016/plano-nacional-de-seguranca-alimentar-e-nutricional-ja-esta-disponivel-nainternet>. Acesso em: 21 out. 2016.

CAXIAS DO SUL. Mapa de Bairros - Lei 6928/2010. Caxias do Sul, 2010. 1 mapa. Disponível em:

$<$ https://www.caxias.rs.gov.br/_uploads/planejamento/sui/sui_bairros_mapa.pdf $>$. Acesso em: 06 nov. 2017.

CELAC - Comunidad de Estados Latinoamericanos y Carineños. CELAC 2025- Seguridad alimentaria, nutrición y erradicación del hambre: Elementos para el debate y la cooperación regionales. Santiago, jul. 2016. Disponível em: 
$<$ http://repositorio.cepal.org/bitstream/han dle/11362/40348/1/S1600707_es.pdf $>$. Acesso em: 21 out. 2016.

CONSEA - CONSELHO NACIONAL DE SEGURANÇA ALIMENTAR E

NUTRICIONAL. Conceitos: Segurança Alimentar e Nutricional e Soberania Alimentar. Brasília, 2015. Disponível em: <http://www4.planalto.gov.br/consea/acesso-ainformacao/institucional/conceitos>. Acesso em: 21 out. 2016.

CRITTENDEN, B.; KOLACZKOWSKI, S. Waste minimization: a practical guide. Inglaterra: Icheme, 1995, $81 \mathrm{p}$.

DIAS, D. M.; MARTINEZ, C. B.; BARROS, R. T. de V. Estimativa da geração de resíduos sólidos urbanos como subsídio para ações voltadas à sustentabilidade ambiental. Revista Brasileira de Ciências Ambientais, n. 33, set. 2014. Disponível em: http://abesdn.org.br/publicacoes/rbciamb/PDFs/33-02.pdf. Acesso em: 20 dez. 2016.

EUROPEAN COMMISSION. Preparatory study on food waste across EU 27. 2010. Disponível em: $<$ http://ec.europa.eu/environment/eussd/pdf/bio_foodwaste_report.pdf $>$. Acesso em: 11 fev. 2016.

FAO - Food and Agriculture Organization of the United Nations. Food Wastage Footprint: Impacts on Natural Resources. 2013. Disponível em:

<http://www.fao.org/docrep/018/i3347e/i 3347e.pdf>. Acesso em: 12 fev. 2016.

GUSTAVSSON, J; CEDERBERG, C.; SONESSON, U.; OTTERDIJK, R. van; MEYBECK, A. Global food losses and food waste: extent, causes and prevention. Swedish Institute for Food and Biotechnology (SIK); Food and Agriculture Organization of the United Nations (FAO), Rome, 2011.

IMECHE. INSTITUTION OF MECHANICAL ENGINEERS. Global Food: Waste Not, Want Not. Londres, 2013. Disponível em: $<$ http://www.imeche.org/Libraries/Reports /Global_Foo d_Report.sflb.ashx>. Acesso em: 21 jan. 2012.

IBGE - Instituto Brasileiro de Geografia e Estatística. Censo 2010: Informações sobre bairros segundo os municípios. Disponível em:

$<$ https://www.caxias.rs.gov.br/planejamento/texto.php?codigo=304>. Acesso em: 06 nov. 2017.

KATAJAJUURI, J.-M.; SILVENNOINEN, K.; HARTIKAINEN, H., HEIKKILÄ, L.; REINIKAINEN, A. Food waste in the Finnish food chain. Journal of Cleaner Production, v. 73, p. 322-329, 2014. Disponível em:

$<$ http://www.sciencedirect.com/science/article/pii/S0959652613009116>. Acesso em: 19 dez. 2014.

KOSSEVA, M. R. Causes and Challenges of Food Wastage. In: Food Industry Wastes. Londres: Academic Press. 2013. Disponível em: http://www.sciencedirect.com/science/art icle/pii/B9780123919212000184. Acesso em: 12 fev. 2016. 
LEGASPE, L. R. O uso racional de sobras orgânicas urbanas na transformação alimentar humana, ração animal e adubo na CEAGESP São Paulo. In: CONGRESSO BRASILEIRO DE CIÊNCIA E TECNOLOGIA EM RESÍDUOS E DESENVOLVIMENTO SUSTENTÁVEL - ICTR 2004 E CICLO DE CONFERÊNCIAS SOBRE POLÍTICA E GESTÃO AMBIENTAL - NISAM 2004, 2004, Florianópolis. Anais... Florianópolis: ICTR, NISAM, 2005. 1 CD-ROM.

MANDELLI, S. M. de C. Variáveis que interferem no comportamento da população urbana no manejo de resíduos sólidos domésticos no âmbito das residências. 1997. $267 \mathrm{f}$. Tese (Doutorado em Educação) - Universidade Federal de São Carlos, São Carlos, 1997.

MARCONI, M. de A.; LAKATOS, E. M. Fundamentos de metodologia científica. 6. ed. São Paulo: Editora Atlas, 2011.

NONENMACHER, S. E. B.; KALSING, R. M. S. Desperdício como tema gerador para um trabalho de educação ambiental no IFC - Campus Concórdia. In: MENDONÇA, A. W.; SIQUEIRA, A. B.; MARCOMIN, F. E. (Org.). Educação, Sociedade e Meio Ambiente no estado de Santa Catarina: múltiplas abordagens. São Leopoldo: Oikos, 2012. p. 85-98.

OKAZAKI, W. K.; TURN, S. Q.; FLACHSBART, P. G. Characterization of food waste generator: A Hawaii case study. Waste Management, 28, 2008, p. 2483-2494.

PISTORELLO, J.; DE CONTO, S. M.; ZARO, M. Geração de resíduos sólidos em um restaurante de um hotel da Serra Gaúcha, Rio Grande do Sul, Brasil. Engenharia Sanitária e Ambiental, v. 20. n. 3, 2015, p. 337-346. Disponível em: < http://www.scielo.br/scielo.php?script=sci_arttext\&pid=S1413-41522015000300337\&1 $\mathrm{ng}=\mathrm{pt} \& \mathrm{nrm}=\mathrm{iso} \& \mathrm{tlng}=\mathrm{pt}>$. Acesso em: 19 nov. 2015.

PORPINO, G.; PARENTE, J.; WANSINK, B. Food waste paradox: antecedents of food disposal in low income households. International Journal of Costumer Studies, v. 39, n. 6, nov. 2015. Disponível em: <http://onlinelibrary.wiley.com/doi/10.1111/ij cs.12207/full>. Acesso em: 21 out. 2016.

RIO GRANDE DO SUL. Decreto $\mathbf{n}^{\circ} \mathbf{3 8 . 3 5 6}$, de $1^{\circ}$ de abril de 1998 . Aprova o regulamento da Lei $\mathrm{n}^{\circ}$ 9.921, de 27 de julho de 1993, que dispõe sobre a gestão de resíduos sólidos no Estado do Rio Grande do Sul. Disponível em:

$<$ http://www.sema.rs.gov.br/sema/html/decrest.htm>. Acesso em: 18 ago. 2006.

SANTOS, R. F. dos. Planejamento ambiental: teoria e prática. São Paulo: Oficina de Textos, 2004.

SONNINO, R.; McWILLIAM, S. Food waste, catering practices and public procurement: a case study of hospital food systems in Wales. Food Policy, v. 36, n. 6, p. 823-829, 2011. Disponível em: <http://www.sciencedirect.com/science/article/pii/S0306919211001163>. Acesso em: 01 jun. 2012.

STANCU, V.; HAUGAARD, P.; LAHTEENMAKI, L. Determinants of consumer food waste behaviour: Two routes to food waste. Appetite, v. 96, p. 7-17, jan. 2016. Disponível em: < http://www.sciencedirect.com/science/article/pii/S0195666315003992>. Acesso em: 27 nov. 2015. 


\section{\#tear}

STEFAN, V.; HERPEN, E. V.; TUDORAN, A. A.; LAHTEENMAKI, L. Avoiding food waste by Romanian consumers: The importance of planning and shopping routines. Food Quality and Preference, v. 28, n. 1, p. 375-381, abr. 2013.

VENZKE, C. S. A geração de resíduos em restaurantes, analisado sob a ótica da produção mais limpa. Disponível em:

$<$ http://www.abepro.org.br/biblioteca/ENEGEP2001_T R104_0127.pdf > . Acesso em: 05 set. 2006.

WILLIAMS, H.; WIKSTRÖM, F.; OTTERBRING, T.; LÖFGREN, M.; GUSTAFSSON, A. Reasons for household food waste with special attention to packaging. Journal of Cleaner Production, v. 24, p. 141-148, mar. 2012. Disponível em: <http://www.sciencedirect.com/sci ence/article/pii/S0959652611004793>. Acesso em: 13 set. 2013.

WRAP - Waste \& Resources Action Programme. We don't waste food! A householder survey. Banbury, UK, 2007. Disponível em: <

http://www.wrap.org.uk/sites/files/wrap/We_don_t_waste_food_A_household_survey_mar_07.db6802f9.6397.pdf $>$. Acesso em: 06 nov. 2017. 